\title{
Loss of Load Expectation of Alkhoms Generating Units
}

\author{
Mohamed Altaher Ben Mouhsen, Ali A. Tamtum* \\ Department of Electrical and Computer Engineering, Elmergib University, Libya \\ * Corresponding author email: aamtamtum@yahoo.com
}

DOI: https://doi.org/10.21467/proceedings.2.29

\begin{abstract}
AlKhoms generating power station is one of the largest stations in the Libyan generation system. It consists of eight units represent approximately $18 \%$ of the Libyan generation capacity. Hence, it is chosen to perform the reliability study presented in this paper. Generation system reliability is an important aspect in the planning for the future system capacity expansion since it provides a measurement to make sure that the total generation system capacity is sufficient to provide adequate electricity when needed. There are two approaches used for generating units reliability, deterministic and probabilistic approaches. The probabilistic approach branches into Monte Carlo simulation and analytical methods which include loss of load expectation (LOLE). The LOLE is the most widely used index in generation adequacy evaluation; it indicates the expected time for which the available generation will not be sufficient to meet the demand. In this paper, a reliability study is performed on Alkhoms generating units. Forced outage rates (FOR) is calculated, annual load data is analyzed, annual load duration curve is constructed and convolved with the generation model, and the (LOLE) is evaluated. The effect of load growth and FOR variation are also considered. A computer program is written in MATLAB as a tool for this purpose and used to construct the annual load duration curve and capacity outage probability table (COPT). the importance of this study comes from the fact that the system consists from non-identical units since the eight units has a different FOR which complicate the evaluation; as well as the fact that the binomial distribution cannot be applied directly while most published studies simplify the evaluation by grouping up identical units
\end{abstract}

Keywords: Reliability study; loss of load expectation (LOLE); Forced outage rates (FOR); Load duration curve.

\section{Introduction}

The fundamental aim of any power utility is to satisfy the system load and energy requirement of its customers at the lowest operating cost with an acceptable level of continuity and quality of electricity supply. In Libya, the General Electric Company of Libya (GECOL) is the power utility responsible for generation, transmission and distribution of the electric power for the whole country. The total installed capacity of the generating units was 6200MW in 2008 which is not sufficient to meet the present peak load.

(C) 2018 Copyright held by the author(s). Published by AIJR Publisher in Proceedings of First Conference for Engineering Sciences and Technology (CEST-2018), September 25-27, 2018, vol. 1.

This is an open access article under Creative Commons Attribution-NonCommercial 4.0 International (CC BY-NC 4.0) license, which permits any non-commercial use, distribution, adaptation, and reproduction in any medium, as long as the original work is properly cited. ISBN: 978-81-936820-5-0 
Alkhoms generating station is one of the biggest stations in the Libyan generation system, it consists of eight generating units with total generating capacity of 1080 MW which represents about $18 \%$ of the Libyan gross capacity. Moreover, its data is available at the station office. Hence, it was chosen to perform this study.

Many papers throughout the world related to LOLE has been published, such as [1], in which the impact of aging characteristics of components on the calculation of reliability indices such as LOLE was described. In [2] the LOLE was evaluated for a proposed test system of six generating units is used, some units has identical FOR and identical capacities with 64 states of available capacity. In [3] a method for generation reliability assessment using intelligent systems was proposed. The effect of varying the load and failure rates on reliability indices was analysed in [4]. The relationship between LOLE and reserve margin was discussed in [5] where the peak load variation curve (DPLVC) with 365 point is used instead of load duration curve for a modified Peninsular Malaysia system consisting of 22 generating units and the LOLE was evaluated in days/year.

In [6], LOLE has been discussed for Alkhoms gas and steam units as two individual subsystems each of them consists of four identical units with 16 states of available capacity.

The object of this paper is to develop techniques to evaluate LOLE for Alkhoms generating system consisting of eight units having different capacities and different FOR with 256 states of available capacities and using a generation model based on a wide range of actual history including 2015 and 2016.

\section{Generation System Reliability.}

Generally; reliability can be defined as the probability of device (or system) performing its purpose adequately for the period of time intended under the operating conditions [7]. Reliability evaluation of a complete power system including generation, transmission, station and distribution facilities is an important in overall power system planning and operation[8]. Due to the enormity of the problem, reliability analysis of each level is performed independently.

Generation system reliability is concerned only to the generating units reliability, assuming that other levels are 100\% reliable. The first techniques of generation system reliability were all deterministic. The most common deterministic approaches are the reserve margin and the largest set in the system[9]. Probabilistic methods can provide more meaningful information to be used in the sign and resources in planning and allocation. There are two main approaches for probabilistic evaluation of power system reliability; analytical methods and Monte Carlo simulation. Analytical techniques represent the system by mathematical methods and use direct analytical solutions to evaluate a priori reliability indices from the model, it includes loss of load expectation (LOLE), loss of energy expectation (LOEE) and frequency and duration method. Monte Carlo simulation estimates the actual random behaviour of the system[10].

Proceedings of First Conference for Engineering Sciences and Technology (CEST-2018), vol. 1 
Loss of Load Expectation of Alkhoms Generating Units

The basic approach for the generating system adequacy consists of three parts as shown in Figure 1.

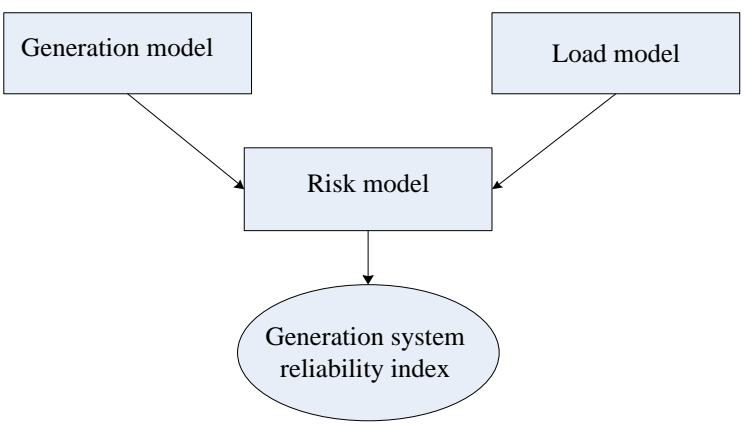

Figure 1: Generating system adequacy

The generation model and the load model are convolved to give the risk model which represent the risk of generation capacity less than load. The adequacy evaluation of the generation system consists of three steps :

- create a general capacity model based on the operating characteristics of the generating units .

- build an appropriate load model .

- combine the generation capacity model with the load model to obtain the risk model.

\subsection{Generation Model (State Space Representation)}

For simplicity, with no derated states considered, generating unit can be reside only in up or down (repair) state as shown in Figure 2.

\begin{tabular}{|c|c|c|}
\hline $\begin{array}{c}\text { Unit up } \\
\text { State } 0\end{array}$ & $\lambda$
\end{tabular}$\quad \begin{gathered}\text { Unit down } \\
\text { State } 1\end{gathered}$

Figure 2: State space diagram of a generating unit

Where: $\lambda$ is the expected failure rate.

$\mu$ is the expected repair rate.

$m$ is the mean time to failure.

$r$ is the mean time to repair.

$\mathrm{T}$ is the cycle time $=m+r$

The term unavailability ( forced outage rate ) can be defined as the probability of finding the unit on forced outage at a certain time in future.

Unavailability $=U=F O R=\frac{\sum(\text { down time })}{\sum(\text { down time })+\sum(\text { rep time })}$

$U=\frac{\lambda}{\lambda+\mu}=\frac{r}{r+m}$

The total number of available (or unavailable) capacity states of an $n$ units system is $2^{n}$ 


\subsection{Capacity Outage Probability Table (COPT)}

In the analytical method, generation model is based on capacity outage probability table which lists system capacity states in increasing order of capacity outage, together with the probability of occurrence of each of these states [11].

If all units have identical capacity and FOR then the COPT can be constructed directly using binomial distribution in the following form:

$(p+q)^{n}$

Where: $p$ is the availability.

$q$ is the unavailability.

$n$ is the number of units.

If all units haven't identical capacity but have identical FOR, binomial distribution cannot be applied directly but we should classify units in groups of tables according to their capacities and FOR and combine identical units using binomial distribution; then combine together one at a time that groups of tables. If the units have different FOR, then the expression of equation (3) becomes as follow:

$\left(p_{1}+q_{1}\right)\left(p_{2}+q_{2}\right) \ldots \ldots \ldots\left(p_{n}+q_{n}\right)$

\subsection{Load Model}

The load model used in an analytical approach is usually either the daily peak load variation curve (DPLVC) or the load duration curve (LDC). The DPLVC includes only the peak load of each day for the period being considered, whereas the LDC includes the hourly variation of the load in this period [8]. Figure 3 shows a typical LDC.

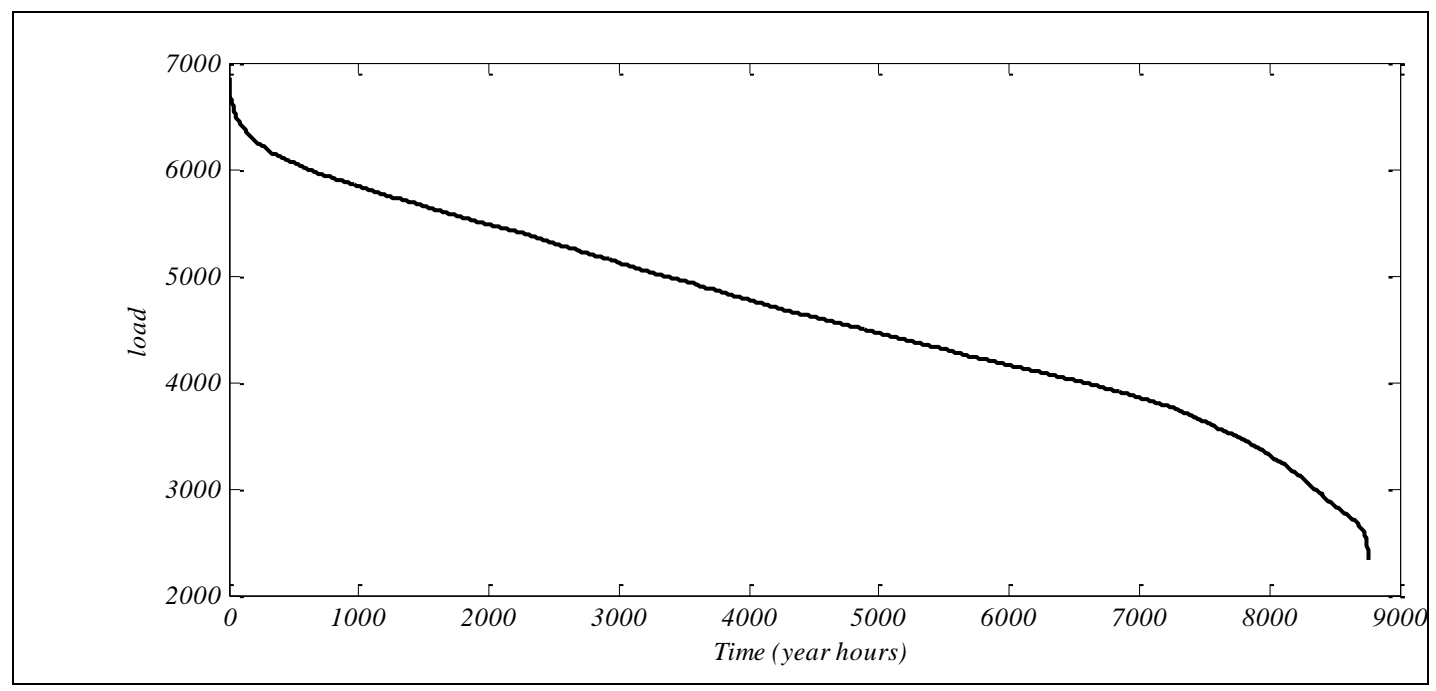

Figure 3: A typical load duration curve 
Loss of Load Expectation of Alkhoms Generating Units

\section{Loss Of Load Expectation (LOLE)}

The term ' capacity outage ' indicates a loss of generation which may or may not result in a loss of load. This condition depends up on the generating capacity reserve margin and the system load level. A loss of load will occur only when the capability of the generating capacity remaining in service is exceeded by the system load level [11]. The LOLE indicates the expected time for which the available generation will not be sufficient to meet the demand [12]. After combining the generation capacity model with the load model ,then the loss of load expectation can be evaluated from the following formula :

$L O L E=\sum P_{k}\left(Q_{k}\right) \cdot t_{k}$

Where: $P_{k}$ is the individual probability of capacity outage of $Q_{k}$.

$Q_{k}$ is the magnitude of the outage in the system capacity outage probability table.

$t_{k}$ is the number of time units in the study interval than an outage magnitude of. would result in loss of load.

$n$ is the number of states of the capacity outage probability table.

\section{Numerical Results}

\subsection{Case study}

Alkhoms generation station consisting of eight units of a total generating capacity of 1080 MW, the FOR is based on two years' operating cycle data. Table (1) illustrates the generation system data[13].

Table 1: generating system data

\begin{tabular}{|c|c|c|}
\hline Unit number & Capacity (MW) & FOR \\
\hline 1 & 150 & 0.012 \\
\hline 2 & 150 & 0.023 \\
\hline 3 & 150 & 0.149 \\
\hline 4 & 150 & 0.029 \\
\hline 5 & 120 & 0.046 \\
\hline 6 & 120 & 0.083 \\
\hline 7 & 120 & 0.024 \\
\hline 8 & 120 & 0.085 \\
\hline
\end{tabular}

\subsection{Simulation Results}

Simulation is carried out using M-File/Matlab software to construct the capacity outage probability table (COPT) of 256 states of available (or unavailable) capacity, load duration curve ( LDC) and evaluate the LOLE index. The capacity outage probability table is given in table (2). 
Mouhsen et al., CEST-2018, AIJR Proceedings 2, pp.244-252, 2018

Table 2: Capacity outage probability table of Alkhoms generating units

\begin{tabular}{|c|l|l|}
\hline $\begin{array}{c}\text { Capacity out } \\
\text { of service (MW) }\end{array}$ & Probability & Cumulative probability \\
\hline 0 & 0.623144721257247 & 1.000000000000000 \\
\hline 120 & 0.159660214366457 & 0.376855278742753 \\
\hline 150 & 0.149954450175113 & 0.217195064376296 \\
\hline 240 & 0.014299685339326 & 0.067240614201183 \\
\hline 270 & 0.038420865720981 & 0.052940928861857 \\
\hline 300 & 0.007994557339277 & 0.014520063140876 \\
\hline 360 & 0.000516996133141 & 0.006525505801599 \\
\hline 390 & 0.003441097035067 & 0.006008509668458 \\
\hline 420 & 0.002048340770630 & 0.002567412633391 \\
\hline 450 & 0.000152806235759 & 0.000519071862761 \\
\hline 480 & 0.000006212499829 & 0.000366265627002 \\
\hline 510 & 0.000124410699863 & 0.000360053127173 \\
\hline 540 & 0.000183456026312 & 0.000235642427310 \\
\hline 570 & 0.000039151541409 & 0.000052186400998 \\
\hline 600 & 0.000000931712604 & 0.000013034859590 \\
\hline 630 & 0.000001494984976 & 0.000012103146986 \\
\hline 660 & 0.000006632737291 & 0.000010608162010 \\
\hline 690 & 0.000003506538714 & 0.000003975424719 \\
\hline 720 & 0.000000238720523 & 0.000000468886005 \\
\hline 780 & 0.000000079702490 & 0.000000230165482 \\
\hline 810 & 0.000000126776703 & 0.000000150462991 \\
\hline 840 & 0.000000021380582 & 0.000000023686289 \\
\hline 930 & 0.000000001523416 & 0.000000002305706 \\
\hline 960 & 0.000000000773002 & 0.000000000782290 \\
\hline 1080 & 0.000000000009289 & 0.000000000009289 \\
\hline & & \\
\hline & & \\
\hline & &
\end{tabular}

The Libyan network load data of 2016 (8760 hours are only considered) with a peak load of $6861 \mathrm{MW}$ is collected from GECOL and since Alkhoms generating units represents $17.4 \%$ of the Libyan generating capacity, it is assumed that it is loaded by $17.4 \%$ of the Libyan hourly gross load, this assumption is considered because no specific unit in the Libyan generating system supplies a specific load but all units participate in the supply of Libyan gross load. The load model for the base case is the load duration curve of 2016 and the LOLE is evaluated in hours/year.

Figures 4, 5 and 6 show the LDC of the years 2016, 2017 and 2018 respectively.

\section{Case 1 (Base case):}

For the year of 2016, with a peak load of 1195 MW and the FOR of table (1), the LOLE is 1159 hours /year. 
Loss of Load Expectation of Alkhoms Generating Units

Case 2:

With an annual load growth of 6\% [14], the peak load is $1266 \mathrm{MW}$, the LOLE of 2017 is 1893 hours / year .

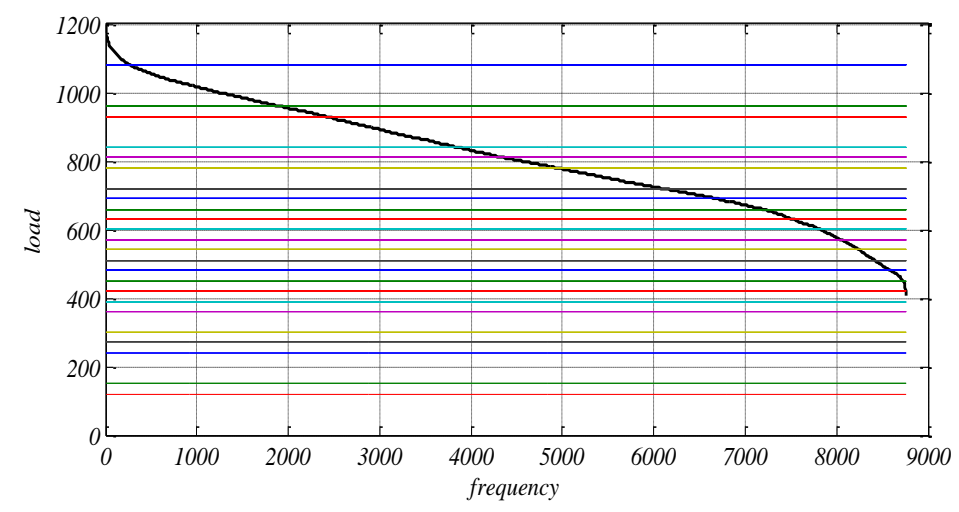

Figure 4: Load duration curve of 2016

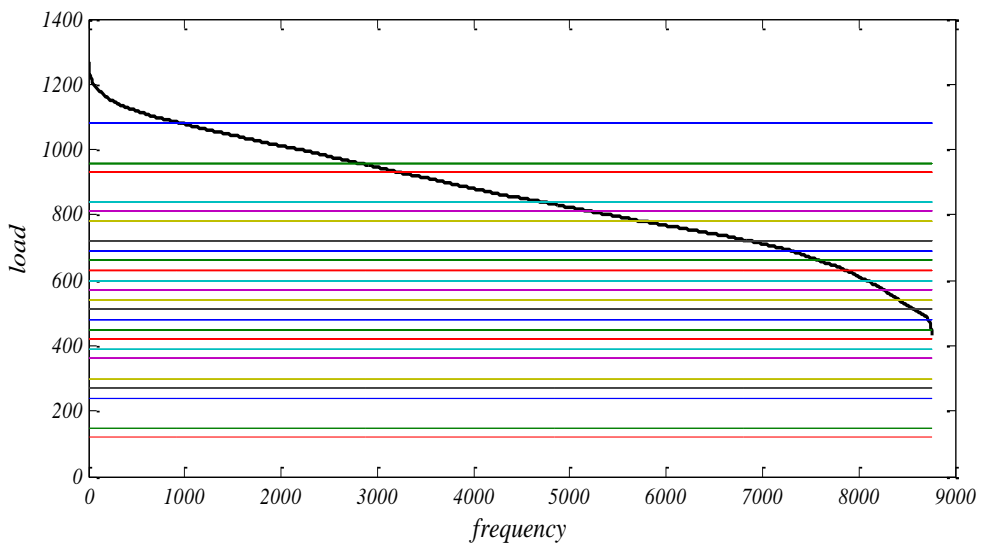

Figure 5: Load duration curve of 2017

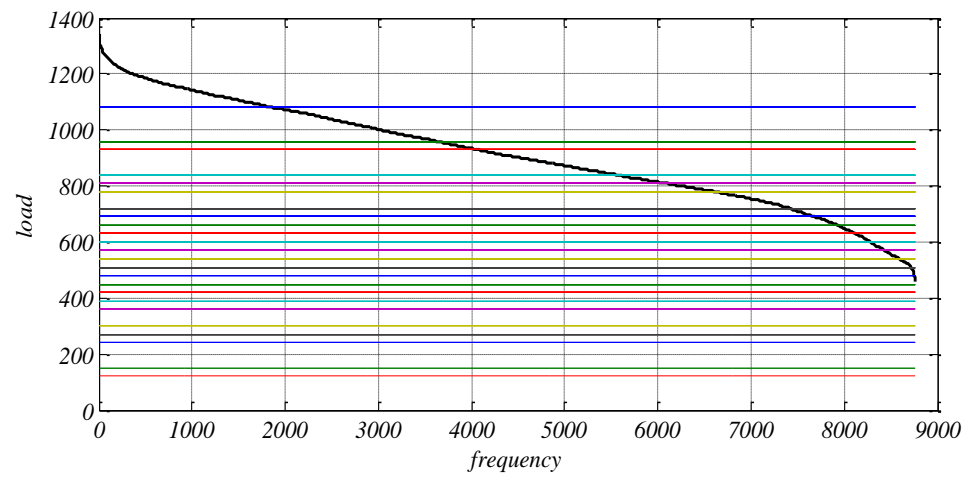

Figure 6: Load duration curve of 2018 


\section{Case 3:}

With an annual load growth of 6\%, the peak load is 1342.86 MW and the LOLE of 2018 is 2806 hours / year.

\section{Case 4:}

Again, for 2018 with the same assumption of case 3 , but considering a reduction of FOR of all units to 0.01,we obtain the modified COPT shown in table (3), and the LOLE of 2018 is $2024 \mathrm{hrs} /$ year.

Table 3: Capacity outage probability table of Alkhoms generating units with FOR=0.01

\begin{tabular}{|c|c|c|}
\hline $\begin{array}{c}\text { Capacity out } \\
\text { of service (MW) }\end{array}$ & Probability & Cumulative probability \\
\hline 0 & 0.922744694427920 & 1.000000000000000 \\
\hline 120 & 0.037282613916280 & 0.077255305572080 \\
\hline 150 & 0.037282613916280 & 0.039972691655800 \\
\hline 240 & 0.000564888089641 & 0.002690077739521 \\
\hline 270 & 0.001506368239042 & 0.002125189649880 \\
\hline 300 & 0.000564888089641 & 0.000618821410839 \\
\hline 360 & 0.000003803960200 & 0.000053933321198 \\
\hline 390 & 0.000022823761198 & 0.000050129360998 \\
\hline 420 & 0.000022823761198 & 0.000027305599801 \\
\hline 450 & 0.000003803960200 & 0.000004481838603 \\
\hline 480 & 0.000000009605960 & 0.000000677878404 \\
\hline 510 & 0.000000153695362 & 0.000000668272443 \\
\hline 540 & 0.000000345814564 & 0.000000514577082 \\
\hline 570 & 0.000000153695362 & 0.000000168762518 \\
\hline 600 & 0.000000009605960 & 0.000000015067157 \\
\hline 630 & 0.000000000388120 & 0.000000005461197 \\
\hline 660 & 0.000000002328718 & 0.000000005073077 \\
\hline 690 & 0.000000002328718 & 0.000000002744359 \\
\hline 720 & 0.000000000388120 & 0.000000000415642 \\
\hline 780 & 0.000000000005881 & 0.000000000027522 \\
\hline 810 & 0.000000000015682 & 0.000000000021642 \\
\hline 840 & 0.000000000005881 & 0.000000000005960 \\
\hline 930 & 0.000000000000040 & 0.000000000000079 \\
\hline 960 & 0.000000000000040 & 0.000000000000040 \\
\hline 1080 & 0.000000000000000 & 0.000000000000000 \\
\hline
\end{tabular}

\section{Conclusion}

Already it is known that the Libyan generation system has no reserve margin, its capacity is less than the present peak load, and it is unreliable. This paper presents a quantitative measure of the risk related to a part of Libyan generation system. The reliability study of Alkhoms generating system was performed using the available data from GECOL. The LOLE index is evaluated for different cases. Cases 1 and 2 showed that the load growth of $6 \%$ leads to 
Loss of Load Expectation of Alkhoms Generating Units

increasing LOLE by 734 hour/year ( $63.33 \%$ ); whereas cases 3 and 4 showed that the reduction of FOR of all units to 0.01 reduces the LOLE by 782 hour/year (27.8\%). For all cases, it is clear that the values of LOLE are very high and violates the acceptable level, this is a direct result of the high loading considered for the units of interest $(17.4 \%$ of the Libyan gross load) and dependent on the used data imported from GECOL. To overcome this bad situation, it is recommended to complete the under construction projects of the Libyan generation system to meet the present load and the future load growth.

\section{References}

[1] Hagkwen Kim, Chanan Singh, "Reliability modeling and Simulation in power systems with aging characteristics", IEEE transactions on power systems, Vol.25, Issue 1, Feb. 2010, P: 21-28.

[2] Mehdi Nikzad, Shoorangiz Shams Shamsabad Farhani, Mohammad Bigadi Tahar, Hossein Tourang, Behrang Yousefpour, "Calculation of generation system reliability index : loss of load expectation", Life Scince Journal, 2012, 9, (4).

[3] H.Haroonabadi, M. R. Haghifam, "Loss of load expectation assessment in deregulated power system using Monte Carlo simulation and intelligent systems", International Journal of Smart Electrical Engineering, Article 3, Vol.01, Issue 01, Winter 2012, Page:17-25.

[4] C. R. Sharada Prasad, Shiddalingappa Ajjampur, Santhosh Raikar M, Prakash MN, "To study the adequacy assessment of generation system", International Journal of advanced research in electrical, electronics and instrumentation engineering, Vol.3, Issue 1, January 2014.

[5] Siti Rasheeka Muhamad Zafir, Noor Miza Muhamad Razali, Tengku Juhana Tenngku Hashim, "Relationship between loss of load expectation and reserve margin for optimal generation planning", Jurnal teknologi (Sciences \&Engineering), 78:5-9 (2016) 27-33.

[6] Marwan M. Alturshany, Loss of load expectation for Alkhoms gas and steam units, "B.Sc graduation project 2017 ", Faulty Of Engineering -Elmergib University.

[7] Roy Billinton, Ronald N., "Reliability evaluation of engineering systems: concepts and techniques", Plenum Publishing (New York), 1984 .

[8] R. Billinton, L . Goel, "Adequacy assessment of an overall electric power system analysis", IEEE proceeding, Vol.139,No.1, Jan 1992 pp 57-63 .

[9] Chanan Singh, "Power system reliability analysis", Texas A,M University.

[10] Jose Faernando prada, "The value of reliability in power systems", Massachusetts institute of technology, Report no. EL 99- 005 WP, July 1999

[11] Ronald N, Allan, Roy Billinton, "Probabilistic assessment of power systems", Proceedings of the IEEE,Vol.88 ,No.2, PP $140-162$, February 2000

[12] Roy Billinton ,Ronald N, Allan, "Reliability evaluation of power systems", Plenum publishing ( New York), 1984.

[13] GECOL "technical reports" 2015-2016.

[14] Fathi Mohamed, Haddoud Abdulnabi Haddod, Bashir Mohamed Jumaa, "Planning of Electrical Networks in GECOL", Energy and Life magazine, No.14, September 2001. 